\title{
La parálisis cognitiva Sumatoria de determinantes socioculturales
}

\author{
Neyla Graciela Pardo Abril' \\ Investigadora-Docente instituto de Estudios en Comunicación y Cultura
}

Edwar Eugenio Hernández Vargas

Psicólogo Universidad Nacional de Colombia

\section{RESUMEN}

Parálisis cognitiva es un esfuerzo teórico por formular planteamientos que permitan comprender las relaciones entre representación, discurso y cognición. En este caso se hace énfasis en el conjunto de procesos discursivos que favorecen la limitación de la comprensión de los fenómenos socioculturales por efecto del impacto de modelos de interacción, que se estructuran como representaciones. Se estudia la espectacularización, la naturalización y el ocultamiento como procesos discursivos que desde la producción emotiva, la perdurabilidad y los vacíos de significados irrumpen en la acción de conocer.

\section{Palabras clave}

Representación, metáfora, cogniciỏn.

\section{Abstract}

Cognitive paralysis is a theoretical effort made in order to establish frameworks to understand the relationships between representation, discourse and cognition. In this case, the emphasis is placed on the group of discursive processes that favour limited comprehension of socio-cultural phenomena, due to the impact of interaction models. Those interaction models are structured as representation. Here, the espectacularization, naturalization and hiding as discoursive processes that, established from emotional production, durability and meaning gaps, burst in the action of knowing.

\section{KEY WORDS}

Representation, metaphor, cognitionion.

1 Doctora en Filología-Lingüística Española. Avance de la investigación: Discurso, cognición y cultura. Grupo Colombiano de Análisis del Discurso Mediático 


\section{Cognición, parálisis y parálisis cognitiva}

La noción de parálisis cognitiva tiene algunos antecedentes: en primer lugar, la reseña de la obra El terrorista, de Daniel Guebel, publicada en el periódico argentino Clarín, en la que se afirma que "El terrorista es la narración de una parálisis cognitiva: la comprensión es imposible"2. En segundo lugar, Anta Félez (1999) considera a la parálisis cognitiva como uno de los tres detonantes que generan la decadencia contemporánea del paradigma científico (los otros dos son la transformación ideológica y política del siglo XX y el relativismo científico).

La parálisis cognitiva es, para esta reflexión, la incapacidad para la comprensión como resultado de un proceso en el que se conjuga emoción, subjetividad, representaciones de los colectivos y formas de ejercicio del poder en la generación de normas subyacentes a las expresiones discursivas. No obstante, en aras de desen-

La parálisis en este caso
es entendida como
la primacía del subjetivismo
sobre cualquier sistema
político y social.
trañar el significado y la forma en que ocurre la parálisis cognitiva en el marco del análisis crítico del discurso se hace fundamental comenzar por una aproximación a lo cognitivo $\mathrm{y}$ al término parálisis.

De acuerdo con Gardner (1985), la ciencia cognitiva se interesa por la naturaleza del conocimiento, abarcando sus componentes, fuentes, evolución y difusión, con lo cual centra su interés en las representaciones mentales. La cognición entonces "debe ser descrita en función de símbolos, esquemas, imágenes, ideas y otras formas de representación mental" (Gardner, 1985: 38). En consecuencia, uno de los focos de interés para la ciencia cognitiva es necesariamente la exploración del contenido de la mente, por lo que el concepto de representación adquiere nuevas dimensiones al abordar el problema más allá de sus aspectos formales. a este respecto, la semán-

\footnotetext{
2 Clarín, 27 de setiembre de 1998, Daniel Guebel cuenta
} los orígenes de "el terrorista". tica cognitiva se soporta en el principio de que el signo lingüístico y su significación es conceptual y que el proceso de conceptualización representa la experiencia perceptiva, no los objetos en sí (Gardber, 1985; Chafe, 1990; Langaker, 1987 y Lakoff, 1980). En este marco el ser humano es capaz de crear representaciones que se expresan en el lenguaje. Dretske (1986) considera que toda representación implica una construcción semántica, de modo que un hecho representa algo si tiene la función de hacerlo.

Las representaciones son conceptos estructurados y coherentes con relaciones internas complejas, cuya principal expresión simbólica se cristaliza en el uso de la lengua. Esto remite a la búsqueda de explicaciones sobre las maneras como el ser humano asigna significado a un objeto físico, encontrándose de modo preponderante un abordaje de lo mental. Von Eckardt (1999) precisa cuatro aspectos esenciales que posee una representación, que son puntos centrales para la explicación de los procesos mentales: la representación y su instanciación en algún medio físico; el contenido que representa uno o más objetos; las relaciones representacionales que están de alguna manera fundamentadas y la posibilidad de ser interpretada por alguien.

Ruth Millikan (1992) retoma algunos elementos de la teoría de la representación de Dretske y ofrece una versión mucho más rigurosa. Ella parte de la siguiente consideración: Si un signo natural tiene la función de indicar algo, debe indicar eso para el organismo que elabora el signo, por lo que lo importante no es solo cómo se producen las representaciones sino cómo se consumen esas representaciones. El carácter funcional de la representación depende de la explicación histórica del origen de la función que se va a explicar y lo que caracteriza a una estructura funcional que pueda recibir una explicación normal del desempeño de una función.

En las discusiones lingüísticas más recientes hay dos posiciones en torno al lenguaje como hecho cognitivo y, en particular, con relación a cómo se concibe el proceso de conceptualización 


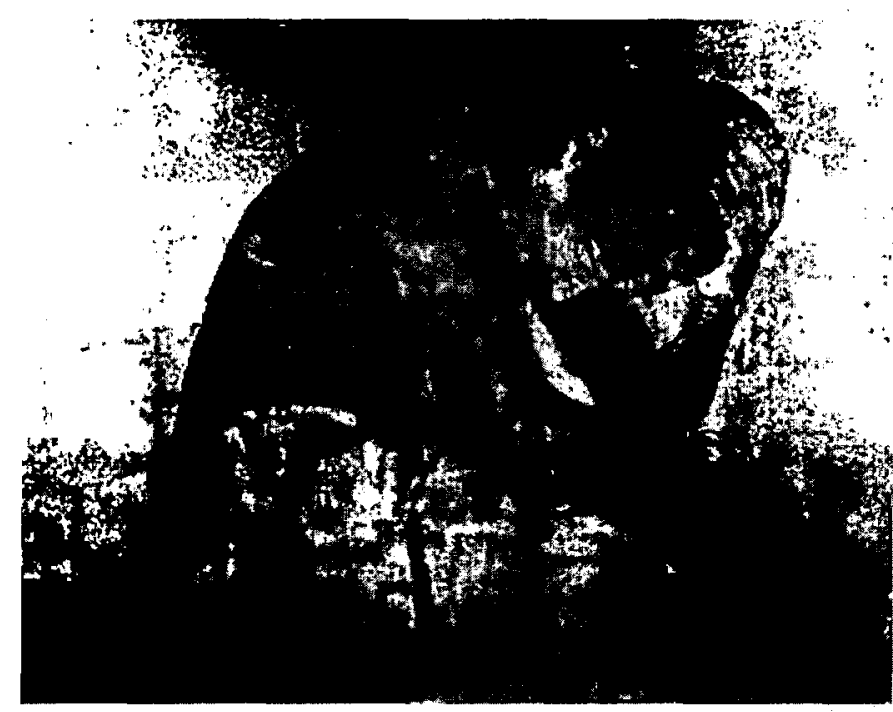

que luego se expresa en el uso de la lengua. Generalizando se puede afirmar que hay, a este respecto, dos puntos de vista: el primero, 'objetivador', de acuerdo con el cual el significado de las palabras puede formularse en términos de un conjunto de condiciones suficientes y necesarias y que los conceptos existen independientemente de la naturaleza corpórea de cualquier organismo pensante y de su experiencia, y el segundo, al cual se denomina "realismo experiencial", sostiene que los conceptos son constructos incorporados que derivan su significado a través de las relaciones que se establecen entre las capacidades de conceptualización - procesadoras de significado-con las funciones psicológicas, perspectiva que da lugar a una postura en la lingüística cognitiva.

En una perspectiva más social, las representaciones son construcciones colectivas de significados que se estabilizan en los dispositivos culturales y las prácticas de las comunidades. En este caso se reconoce la existencia de un tipo de cognición social, que implica un bagaje de significados compartidos presentes en las interacciones comunicativas, los cuales orientan las prácticas sociales y contribuyen a la formación conjunta de la realidad, en virtud de su capacidad para estructurar las representaciones (Agustinos y Walker, 1995). Para efectos de las explicaciones en torno al significado y funcionamiento de la parálisis cognitiva, se hace fundamental la comprensión de algunos de los mecanismos de funcionamiento de la cognición social en función de la construcción de representaciones, tal como se anota más adelante.

En la aproximación a la cognición desde una perspectiva lingüística se destacan dos tesis: la competencia lingüística nó es autónoma del conocimiento humano o enciclopedia, y las propiedades de los conceptos proceden de las capacidades biológicas y psíquicas del ser humano, junto con la experiencia del ser en un ambiente físico-social determinado. La idea fundamental que está detrás de estas posturas es que el ser humano al conceptualizar su realidad crea representaciones, modelos cognitivos o esquemas que rigen el uso que los hablantes hacen de los códigos disponibles; en otros términos, las visiones de mundo son esencialmente modelos cognitivos, lo cual pone en evidencia una ruta para la comprensión de la relación entre el lenguaje y la cultura. Gracias al desarrollo teórico de estas hipótesis lingüísticas es posible identificar dos teorías recientes: la teoría de la relevancia de Sperber y Wilson (1986/1994) y el realismo experiencial de George Lakoff (1987). Para efectos de este documento interesa más la teoría del realismo experiencial, de acuerdo con la cual "La mente está inherentemente corporizada" (Lakoff y Johnson, 1999). Esto significa que es necesario un cuerpo para tener mente y un hallazgo más relevante aún, que la racionalidad se encuentra delineada por la estructura física en la que tiene lugar, es decir, por el sistema visual y motor, por los mecanismos cognitivos y neurales. De manera que la universalidad de la razón pasa a identificarse con los rasgos compartidos de los cuerpos de la especie humana y los ambientes en los cuales el pensamiento se hace posible.

En consecuencia, la concepción de persona de Lakoff y Johnson (1999) implica la existencia de una razón corporizada en la que el sistema conceptual integra ỳ usa el sistema neuronal y está privilegiadamente determinado por los sistemas perceptual y motor. Esto se observa de manera preponderante en los conceptos básicos, de ahí que los conceptos más complejos en tanto congregan conceptos básicos son elaboraciones representacionales del mundo que se encuentran arraigadas a la corporalidad. Además, el sistema conceptual es pluralista, con gran cantidad de estructuracio- 
nes de conceptos abstractos. Esto ocurre porque las metáforas conceptuales, los prototipos, los esquemas, entre otras formas de representación, estructuran los conceptos abstractos de múltiples formas. Sumado a lo anterior se encuentra que las formas de inferencia racional son concretizaciones de inferencia sensoriomotora.

Lakoff y Johnson (1999) afirman que la corporización de los conceptos se hace evidente en la categorización, la cual ocurre en la experiencia misma y, en consecuencia, no existe algo así como una experiencia pura del mundo con independencia de la conceptualización. Esta categorización supone unos conceptos de nivel básico más ligados con la experiencia corporal, cuyo desligamiento de las propiedades físico-químicas y de los dispositivos biológicos para su captación suponen la elaboración de algunas categorías prototipo, es decir, esquemas-imagen estables, que llegan a involucrar patrones fijos de interacción motora. Además, para su elaboración los conceptos requieren nociones espaciales en las que existe un esquema-imagen, un contorno en el que se ubica y una estructura de signo trayectoria.

La experiencia depende también de estructuras cognitivas más complejas a las cuales Lakoff (1987) denomina Modelos Cognitivos Idealizados (MCI), que se forman a partir de las relaciones entre conceptos de nivel básico y de esquema-imagen'. Los MCI son la expresión de la capacidad humana para conceptualizar y forman parte fundamental de las estructuras conceptuales de las cuales disponen los seres humanos para dar sentido a su experiencia. Tanto los conceptos de nivel básico como los de esquema-imagen son el sistema de salida del procesamiento cognitivo y como tales, son la base de la cognición.

Los MCI constan de cuatro modelos en relación: el primero es la estructura proposicional, entendida como un modelo cognitivo en el que se especifican elementos, própiedades y relaciones entre las proposiciones constitutivas; el segundo, la estructura esquemático-imaginística en el que se especifican imágenes esquemáticas como trayectorias, contenedores, formas, rutas, secuencias, entre otras; el tercero, las proyecciones metafóricas, que son relaciones que van de un modelo a otro en un dominio sobre la estructura de otro dominio; $y$, por último, las proyecciones metonímicas, que son modelos que se comportan como los anteriores con la diferencia de que la relaciones entre los elementos del modelo son internas y se prioriza un elemento (Lakoff, 1987).

Coligiendo para efectos de la pretensión de este texto, la cognición es el procesamiento, construcción y uso de representaciones que hacen los individuos con base en el bagaje de significados compartidos e individualmente apropiados. La apropiación conceptual es una conjunción de experiencia y conceptualización en la que la elaboración de la realidad pasa necesariamente por las posibilidades que deja el cuerpo y se extiende a nuevas experiencias en función de las posibilidades de desplazamiento conceptual que establecen algunos modelos cognitivos como las metáforas. De modo que se tiene una versión de lo que implica hablar de cognición, pero para comprender la parálisis cognitiva también es necesario darle un vistazo al significado de parálisis.

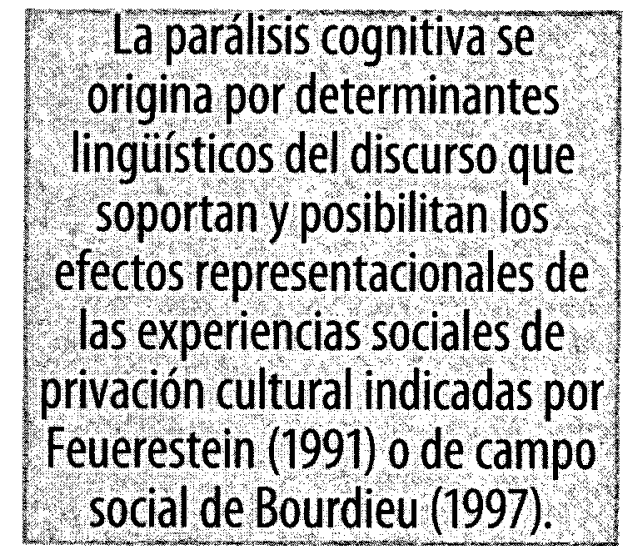

Ahora bien, la noción de parálisis remite a incapacidad de acción, en tanto se entiende como una condición causada por una lesión cerebral congénita en las zonas de control motor, que implica la reducción de la acción por efecto de automatismos, la incapacidad para relajar los músculos, la presencia de movimientos involuntarios que enmascaran e interfieren con los movimientos normales del cuerpo, la reducción del equilibrio corporal, la generación de una marcha insegura y la producción de dificultades en la coordinación, con evidente variabilidad de las afecciones en función del sector y tamaño de la lesión.

En este sentido, hablar de parálisis cognitiva implica necesariamente generación de incapacidad para la acción de conocer. Dado que 
dicha incapacidad desde la medicina se relaciona con lesión congénita, la búsqueda de su equivalente en el discurso es posible hallarla en los recursos lingüísticos que estructuran procèsos discursivos; en consecuencia, la parálisis cognitiva se origina por determinantes lingüísticos del discurso que soportan y posibilitan los efectos representacionales de las experiencias sociales de privación cultural indicadas por Feuerestein (1991) o de campo social de Bourdieu (1997).

Si bien es cierto que Feuerestein (1991) reconoce el papel del cuerpo en la elaboración conceptual, los resultados de su trabajo investigativo en relación con el Programa de Enriquecimiento Instrumental y de los conceptos de Experiencia de Aprendizaje Mediado y Modificabilidad Cognitiva Estructural invitan a la valoración de la experiencia y el papel del mediador como impulsador del desarrollo cognitivo, que permite la superación de condiciones socioculturales adversas que reducen las habilidades cognitivas. Cabe resaltar que esta posición tiene una base teórica que conjuga teorías cognitivas con supuestos epistémicos contrarios en función de resultados clínicos importantes (teoría de procesamiento de la información y la postura culturalista vigoskiana). En este sentido, para la teoría de la Modificabilidad Cognitiva Estructural existe un conjunto de herramientas presentes en la cultura que son internalizadas por las personas, cuyo modo de utilización ha sido adecuadamente transmitido por el mediador. En los casos en los cuales los individuos presentan pocas habilidades cognitivas, su explicación recae sobre el mediador o sobre las condiciones culturales que rodean al sujeto que conoce. En el primer caso, el mediador carece de las características básicas para impulsar los procesos de comprensión y, en el segundo caso, el medio posee en sí mismo un conjunto de elementos que imposibilitan la comprensión de la realidad.

El concepto de privación cultural implica entonces la carencia ambiental de bagajes de significación suficientes para la elaboración de formas de comprensión de la realidad. Esta noción puede ser potenciada por lo que Bourdieu (1997) denomina campos, es decir, el conjunto de condiciones espacio-temporales en las que se ponen en relación lo institucional y lo individual, los intereses y las metas de un colectivo jerarquizado en virtud de sus capitales y de las relaciones de poder que le son inherentes. Desde esta perspectiva, la construcción social de la realidad que rodea y es apropiada por los sujetos posee un conjunto de capitales y relaciones que conforman un bagaje de significaciones y modos de proceder socialmente compartidos que privilegian unos elementos del entorno sobre otros. Así por ejemplo, un campo podría estar formado por los pobres, sujetos que se asume tienen unas carencias materiales; de modo que cuando se hace referencia a la superación de la pobreza, cobra relevancia el cubrimiento de necesidades frente a otros aspectos $y$, en consecuencia, es probable que se encuentren privados culturalmente de una amplia gama de recursos simbólicos necesarios para la comprensión de la realidad desde una óptica diferente a la realidad inmediata y las condiciones espacio-temporales concretas del entorno.

Al reconocer la realidad como una construcción social individualmente apropiada y al discurso como el lugar tangible de su formulación en función de su capacidad para elaborar, transmitir, mantener y modificar representaciones es viable plantear la existencia de procesos referidos al discurso que hacen posible la cognición. Estos procesos se organizan y jerarquizan en función de intereses, propósitos, recursos disponibles y distribuciones del poder presentes en la cultura y en las prácticas sociales. En consecuencia, para comprender la parálisis cognitiva es fundamental reconocer los procesos discursivos que interfieren en la capacidad de conocer. En este caso, se intuye que los procesos de orden discursivo de espectacularización, naturalización y .ocultamiento impiden el desarrollo de las acciones necesarias para elaborar, procesar e interpretar representaciones.

\section{Funcionamiento de la parálisis cognitiva}

De acuerdo con las aproximaciones iniciales al concepto de parálisis cognitiva, sus origenes, en función del campo y la privación cultural, se encuentran en la subjetividad, específicamente en la emoción, en las representaciones sociales instauradas en los colectivos, en las formas de ejercicio 
de poder y en la gramática del discurso. En consecuencia, la comprensión de la parálisis cognitiva como resultado de la construcción discursiva obliga al análisis de los contenidòs o saberes presentes en el discurso, al modo como son comunicados y al modo en que es procesado el discurso.

A este respecto se considera que un discurso genera parálisis cognitiva cuando el contenido se centra en la reconstrucción de imágenes y emociones sin análisis de sus significados, el contexto comunicativo que se estructura se centra en la preservación de representaciones prototípicas al tiempo que intenta formular la realidad social como un hecho natural, y el procesamiento se ve debilitado por el ocultamiento de información que se estima necesaria. La parálisis cognitiva implica una interferencia en el proceso de conocer que impide la comprensión de la realidad. Las fuentes de dicha interferencia surgen de la espectacularización del contenido, la naturalización de la representación o en vacíos de significación necesaria para el procesamiento.

\section{Bloqueo reflexivo del discurso sensacionalista}

El contenido del discurso remite a su significación, es decir, al conocimiento que transporta y construye. En este caso, la parálisis cognitiva surge cuando la conștrucción discursiva se centra en la reconstrucción de los acontecimientos haciendo hincapié en el conjunto de emociones experimentadas por agentes o pacientes del discurso, de tal manera que unidades léxicas referentes a miedo, amenaza, suspenso, entre otras, se convierten en el foco de atención. Tal como lo indican los experimentos de atención selectiva realizados por Williams, Mathews y MacLeod (1996) y MacLeod y Mathews (1988) se da un sesgo atencional hacia estímulos aversivos $o$ amenazantes que interfieren en el procesamiento de información que le compite. El discurso funciona como estresor, frente al cual el organismo tiene tres reacciones posibles: enfrentamiento, huida y parálisis.

$\mathrm{El}$ miedo constituye una de las principales emociones paralizantes, de modo que no es de extrañar que una construcción discursiva generadora de parálisis cognitiva sea precisamente aquella que reconstruya detalle a detalle cada una de las emociones, sentimientos y acontecimientos. En el caso de las noticias, es usual encontrar algunos reportajes que describen a minucia los acontecimientos, de tal modo que el lector se ubica mentalmente en escena y vivencia lo experimentado por los agentes y pacientes del discurso. En los casos en los cuales el lector se ubica en escena, con seguridad los estímulos amenazantes o los estresores cobran mayor relevancia que los contenidos de la información y se tiene como resultado ira (emoción que dispone para el ataque) o miedo (emoción que dispone para la huida o para la parálisis). En todo caso, la puesta en marcha de todo un dispositivo emotivo se hace antagónico de los elementos reflexivos que acompañan la lectura.

La siguiente noticia permite ilustrar de manera sencilla el modo como se propone la espectacularización de los acontecimientos.

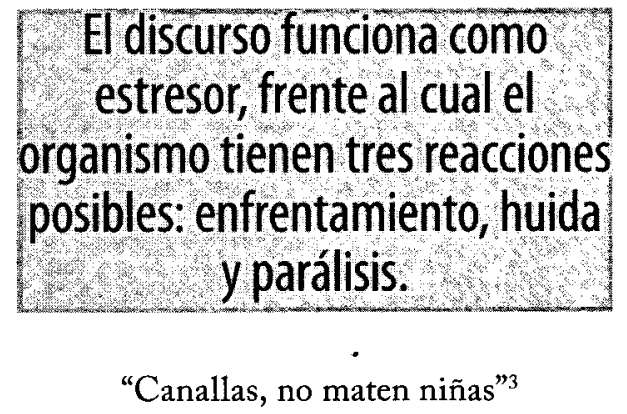

"Son unos locos que le disparan a una niña y vengan del bando que vengan, que me busquen a mí y que me asesinen, pero que no sean canallas, que no asesinen mujeres indefensas... Que tengan alma”. Consternado, después de recibir el cadáver de su hija Ángela María Vásquez Lopera, su padre, Rodrigo Vásquez, no tuvo más palabras para reclamar un atropello de la guerrilla contra la población civil. .

Ángela, al igual que la menor Carolina Amaya García y Adriana María Quintero $\mathrm{Zu}$ luaga, fueron asesinadas durante un reten subversivo en el sitio Don Diego, en un cruce que conduce a los municipios de La Ceja, el sector de Llanogrande en Rionegro y a Medellín en 3 El Espectador, 22 de septiembre de 1998. "Canallas, no
maten niñas". Editorial. 
el Oriente antioqueño. Allí también fueron secuestradas seis personas.

"Lo que yo siento no se describe porque este país está condenado al fracaso. Haỳ una cantidad de corruptos y de violentos que están locos. No creo tener palabras diferentes a esas. El país tiende hacia la anarquía y el caos total. Esa es mi opinión", seguía comentando una y otra vez en la sala de velación del cementerio Campo de Paz de Medellín el acongojado padre quien abrazaba a su esposa Nidia queriendo devolver el reloj hasta la tarde del sábado cuando su hija estaba viva. Ángela María Vásquez, estudiante de noveno semestre de Medicina en la Universidad Pontifica Bolivariana, se disponía a regresar el domingo a las siete y treinta de la noche a Medellín en compañía de su novio después de descansar en una de las fincas de recreo del sector de Llanogrande en Rionegro.

Infortunadamente, cuando llegó al sitio Don Diego, situado a 35 minutos de Medellín se encontró con un grupo de hombres armados que no perdonaron el hecho de que un vehículo tratara de escapar de un reten de "pesca milagrosa”. "A Ángela la obligaron a descender del vehículo para llevársela y como no quiso hacerlo la fusilaron", relato un testigo.

Adriana María Quintero Zuluaga, secretaria de la Fiscalía Seccional de La Ceja, quien en ese momento con sus dos hijas de 10 y 13 años se proponía llegar a la finca de su novio ubicada en el municipio del El Retiro fue otra de las víctimas fatales de este hecho. "Le volvieron el carro nada. No me explico como no mataron a las niñas. Cuando nos asomamos estaban las dos niñitas abrazadas a su madre, con sus caras ensangrentadas y tapándose los oídos", comento Aura Botero, una de las empleadas de un estadero cerca al lugar donde se registraron los hechos.

El ataque guerrillero no terminó ahí: a escasos kilómetros en el sitio El Chuscal, la crueldad cobro una nueva víctima: Carolina, una menor de 17 años quien se dirigía del municipio de La Ceja al de El Retiro en una motocicleta en compañía de su amigo Elkin.

La menor y su amigo fueron socorridos por un sacerdote ceca al seminario Siervos de
María. "Yo los encontré sin saber que hacer y de inmediato nos montamos en el carro y nos dirigimos al hospital de La Ceja a donde no alcanzó a llegar con vida", explicó el cura.

Elgrupo secuestró a María Fernanda Sabaski Ovalle (estudiante, menor de edad); Juan Manuel Cano Escobar (universitario); Fredy López Tabares, conductor; Jorge Enrique Garces, universitario; Maximiliano La Torre.

La narración permite reconstruir escenas puntuales y fragmentadas del acontecimiento, mientras la reflexión y el análisis se eliminan para privilegiar detalles con los cuales se describen los acontecimientos. Así, descripciones como las que siguen no contribuyen de manera importante en la comprensión del fenómeno social representado en la narración, pero sí remiten emocionalmente al lector al pánico que puede generar este tipo de situación: "A Ángela la obligaron a descender del vehículo para llevársela $\mathrm{y}$ como no quiso hacerlo la fusilaron" y "Le volvieron el carro nada. No me explico cómo no mataron a las niñas. Cuando nos asomamos estaban las dos niñitas abrazadas a su madre, con sus caras ensangrentadas y tapándose los oídos”.

La espectacularización se centra en la descripción y construcción de las escenas referidas. En este caso, se enfatiza en adjetivaciones que dan relevancia a la inseguridad y al dolor, las cuales se construyen como estímulos peligrosos y amenazantes cuya representación se pone de relieve en la noticia. Así, expresiones del tipo, "Son unos locos que le disparan a una niña", son la representación de una acción desproporcionada de parte de actores armados como la guerrilla, que ponen de manifiesto condiciones sociales que escapan al control de la sociedad. Todo esto se enfatiza con adjetivos como "canallas" o "mujeres indefensas", con base en los cuales se afianza la distinción entre irracionales-victimarios-bárbaros-despiadados y víctimas-indefensos. Además, se propone un código de honor presente en la construcción de la guerra; de acuerdo con el cual es viable el enfrentamiento y muerte en batalla de hombres, mientras se excluye a mujeres e infantes, entre otros aspectos, porque se les considera más débiles: "Son unos locos que le disparan a una niña y vengan del bando que vengan, 
que. me busquen a mí y que me asesinen, pero que no sean canallas, que no asesinen mujeres indefensas... Que tengan alma”.

E1 dolor frente a la situación es reconstruido mediante consternado después de recibir el cadáver de su bija, no tuvo más palabras, "Lo que yo siento no se describe porque este país esta condenado al fracaso...". En este caso, la imposibilidad de expresar las emociones y de hacer la descripción de las sensaciones se pone de manifiesto para indicar la implicación psíquica de la situación. Es tal el daño producido, que el organismo carece de recursos cognitivos para dar cuenta del mismo. La descripción de la escena incluye representaciones en las que el resultado es un castigo a la desobediencia y la resistencia "hombres armados que no perdonaron el hecho de que un vehículo tratara de escapar de un. reten de "pesca milagrosa", "A Ángela la obligaron a descender del vehículo para llevársela y como no quiso hacerlo la fusilaron". La espectacularización permite que por medio de aprendizaje vicario o por modelamiento se perciba la amenaza de obtener resultados negativos ante acciones de huida o de enfrentamiento, dejando como única alternativa la sumisión.

Sumado a lo anterior se encuentran elaboraciones hipotéticas que ponen de manifiesto lo amenazado: la vida, "No me explico cómo no mataron a las niñas". La vida es, en últimas, el valor preciado de todo individuo que soporta las reacciones de enfrentamiento, huida o sumisión en las distintas especies. Esta sumisión dejada como única alternativa también es ilustrada en relación con los testigos, quienes se convierten en espectadores incapaces de acción frente a acciones ejercidas con violencia por parte de los actores armados. Así, en el discurso se encuentran representaciones como "los agresores son irracionales"; "la victimización no tiene limite"; "la resistencia es castigada"; "pérdida de seguridad", que convergen en la formulación de acciones promotoras de una condición de amenaza a la supervivencia y, en consecuencia, demandantes de respuestas de sumisión e incapacidad de acción para su superación.

Como ya se ha indicado, lo que caracteriza la representación discursiva del acontecimiento en esta noticia es su fragmentación y la caren- cia de las relaciones analíticas que den cuenta del significado del conflicto armado y sus acciones y secuelas, por lo que la representación se elabora desde una gama de sensaciones que desvían la atención y bloquean la posibilidad de comprender y conceptualizar las implicaciones sociopolíticas y culturales de la noticia. En este sentido, hay una representación relevante en tanto la defensa de la vida se impone como condición de convivencia social, pero incompleta si se observa que prevalecen los detalles que movilizan el miedo, el terror y el sometimiento con lo cual se elide la reflexión crítica.

\section{Así han sido y sequirán siendo las cosas: naturalización}

La parálisis cognitiva también es resultado de la naturalización de las representaciones. La naturalización discursiva implica el conjunto de conocimientos e interacciones en las que los objetos del discurso son dotados de existencia propia, incuestionable, independiente de las circunstancias, razonable y normalizada socialmente. En estos casos se tiende a presentar los objetos, personas y acontecimientos en términos de una gama de características formuladas como esenciales, tal como ocurre cuando se fija la atención en los estereotipos de grupos humanos y se anulan sus diferencias individuales.

La naturalización también se estructura al tratar en el discurso a los conceptos que tienen alto nivel de complejidad y abstracción como si fueran objetos del mundo tangible; así, por ejemplo, las personas bien pueden convertirse en armas o fichas, entre otros, cuando se hace referencia a un conflicto social y político. En la mayoría de casos la naturalización favorece que se reduzca la heterogeneidad y complejidad de la realidad y genera la impresión de que lo expresado en el discurso es inmodificable y vigente en cualquier época. La naturalización es en términos coloquiales 'así es', 'así ha sido' y 'así seguirá siendo, porque sí. Este reduccionismo en la representación de lo social a lo material, para explicarlo como cualquier fenómeno de la naturaleza, provee el marco de referencia necesario para emplear los mismos parámetros de interpretación. De modo que la cotidianidad, la 
realidad social y discursiva, se estima obligada a cumplir universales o ciertas regularidades. Ese mundo material aplicado a todo ámbito se hace incuestionable, obvio e inevitable.

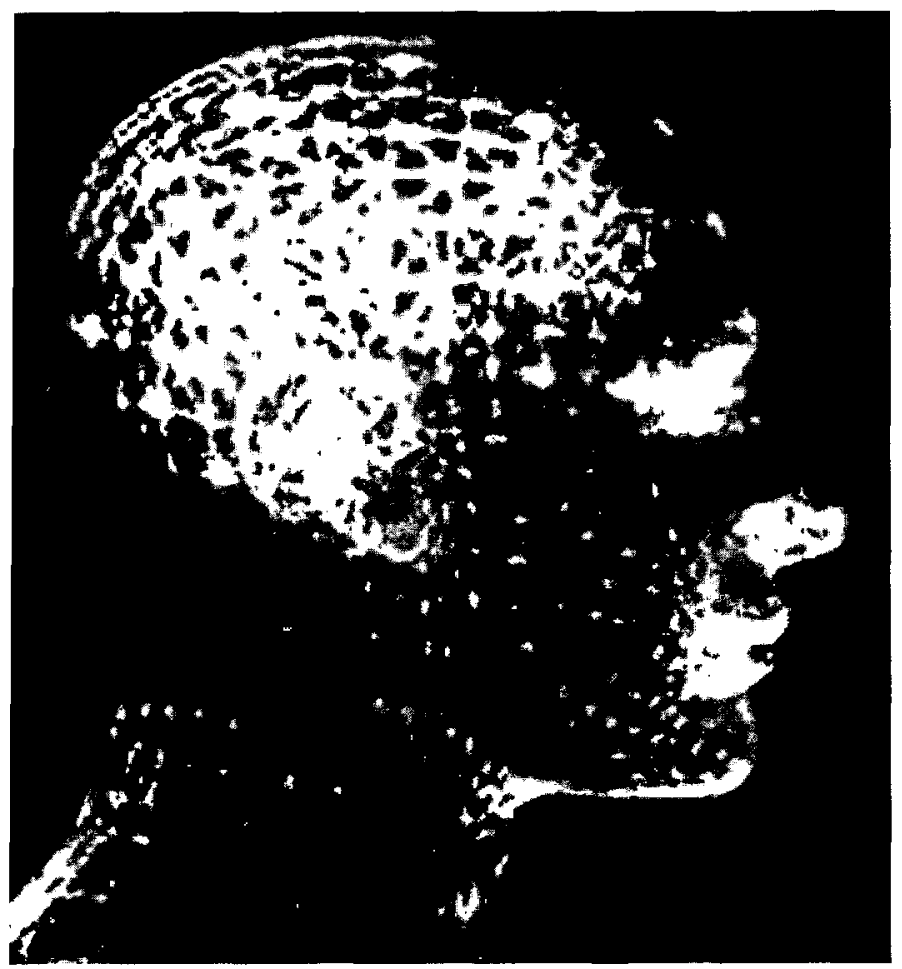

La parálisis cognitiva, en este caso, puede explicarse de cierta manera por un funcionamiento social o individual de la denominada desesperanza aprendida, de acuerdo con el cual, frente a la inexistencia de control de los efectos por emisión conductual el individuo opta por no dar respuesta alguna frente a los estímulos que se le presentan. En la medida en que la naturalización conduzca a lo inmodificable, lo perdurable y lo normal las posibilidades de respuestas $\operatorname{cog}^{-}$ nitivas comienzan a reducirse. Así, por ejemplo, "en la larga historia de violencia del pais", donde "las múltiples negociaciones no tienen resultado alguno' y "todos parecen tener un gen de la violencia", se condensan los principales mecanismos de naturalización de la violencia y una explicación que ha terminado por cobrar peso y justificar las conductas "somos un pais violento". En la siguiente nota de opinión se observa cómo se da el proceso de naturalización de la posición y privilegios de la oligarquía o élite política colombiana. Naturalización que se hace completamente explícita con "Nada de ello es nuevo. Todos sabemos que éste no es un país sino un club manejado por un puñado de familias y una oligarquia cada vez más rica".

\section{Club Colombia ${ }^{4}$}

Confirmado: un país injusto manejado por una oligarquía.

Tengo por saludable leer ocasionalmente periódicos populares, de esos cuyas noticias son tan sensacionalistas que no se enfrían sino que se coagulan, pues allí veo a los colombianos pobres, que suelen estar ausentes en muchas de las demás publicaciones. En esas páginas salen sus dramas y se ofrece una medida humana del país que realmente somos: los padres que abandonan a su hijo recién nacido al pie de un cajero automático para que lo recoja una persona pudiente... El muchacho que compra con sus ahorros un cuchillo en Unicentro y enseguida se suicida con él... Las casas nuevas para desplazados en Medellín, calificadas de "indignas" por la Personería... Las miles de familias que viven sin comida y entre charcos en Cartagena, mientras la alcaldía desaprovecha subsidios por 18.500 millones de pesos... Los indígenas hermanos asesinados en Ginebra (Valle)... Los bogotanos del sur que perdieron en una creciente del río Tunjuelito lo poco que tenían...

Esa Colombia que lucha por subsistir en medio de la más degradante miseria que afecta a la mayoría del país. En los últimos días algunos estudios y foros ofrecieron una radiografía estadística de aquella realidad que los periódicos populares cuentan en carne viva. Los pobres pagan más por los servicios públicos, consumen cada vez menos y son cada vez más pobres. Según Planeación Nacional, el 52,6 por ciento de la población nacional vive en circunstancias marginales.

Alega el Gobierno que ha bajado el desempleo, y es verdad. Pero los puestos que se ofrecen suelen ser precarios $y$ a veces en condiciones de franca explotación. Así lo quiso la Ley 50 de 1990, gentil regalo para los empresarios. E1 43 por ciento de los ocupados percibe menos que el salario mínimo, y el 60 por ciento

4 El Tiempo, 7 de diciembre de 2005. "Club Colombia". Opinión, Cambalache. 
de los trabajadores urbanos se desempeña en el incierto sector informal. En el campo -donde abundan la violencia y la ruina por la competencia de importaciones subsidiadas- la situación es más grave: en cinco años, la pobreza subió del 66 al 69 y la indigencia del 25 al 28.

El crecimiento de los últimos tiempos beneficia casi exclusivamente al bolsillo de los ricos. Las clases medias y pobres aumentaron del 65 al 70 por ciento. El índice que mide el abismo social entre los que tienen y los que no tienen sitúa a Colombia en los últimos lugares mundiales. Las raíces de la injusticia social colombiana son seculares, pero el modelo alcanzó su apogeo con el esquema neoliberal aplicado a partir de 1970. El profesor de la U.N. Jairo Estrada lo califica de "debacle económica y social". Fue cuando retrocedimos hasta la retaguardia de América Latina.

Como el actual Gobierno aplica la misma fórmula, con apenas leves retoques, la aplanadora seguirá su marcha. $Y$ como la economía se deteriorará en el 2006 y el TLC espera agazapado, asoman tiempos peores.

Nada de ello es nuevo. Todos sabemos que este no es un país sino un club manejado por un puñado de familias y una oligarquía cada vez más rica. Lo peor es que los herederos empiezan a pedir turno. El joven Santiago Pastrana, hijo de Andrés y nieto de Misael, dice que quiere ser presidente. Parece un chiste. Pero cuando lo dijo Andrés, hace años, también parecía un chiste. Y se volvió realidad, como ocurre con los peores chistes en este club.

Qué historia la nuestra. Qué futuro nos aguarda.

Una explicación de la parálisis cognitiva como resultado del proceso de naturalización se hace más precisa en la medida en que se revise la noción de desesperanza aprendida, después de haber identificado las características y modos como se propone en el discurso la naturalización. Para que un conjunto de expresiones formen parte del proceso de naturalización es fundamental que favorezcan el tratamiento y comprensión de lo social con los mismos parámetros de los eventos físicos, químicos o biológicos. En este caso, la dirección política, económica y social del país es reconocida en un pequeño grupo de personas, pero la nación es propuesta como un objeto, en tanto es 'manejado'. La oligarquía conserva su lugar de organismo actuante mientras el 'paîs' es transformado en actor pasivo sobre el cual recaen las acciones.

En el artículo se encuentran expresiones del tipo: [pobres] "que suelen estar ausentes en muchas de las demás publicaciones, se ofrece una medida humana del país que realmente somos, Esa Colombia que lucha por subsistir en medio de la más degradante miseria que afecta a la mayoría del país". Estas expresiones presentan en común el uso de la generalización para referirse a la nación colombiana o a segmentos poblacionales que se consideran desempoderados. Así, la marginalidad de la vida pública, los rasgos inhumanos como elementos de identidad, la conjunción de la nación bajo la unidad léxica país, contribuyen con la formulación de un estado de relaciones universal a la población colombiana, en el que sin distinción alguna y a la manera de adherencias intrínsecas de la colombianidad lo normal, la ley universal es un ser 'desapiado' y 'marginal'. En este caso la universalización da cuenta del establecimiento vigente en la estructura social del país.

La efectividad de la naturalización como generadora de parálisis cognitiva se alcanza cuando una vez formulado un estado de cosas normal, universal y seguidor de la lógica que orienta el mundo físico, químico y biológico se sostiene que es inmodificable y perdurable. En el artículo se propone entonces que:

Como el actual Gobierno aplica la misma fórmula, con apenas leves retoques, la aplanadora seguirá su marcha. $Y$ como la economía se deteriorará en el 2006 y el TLC espera agazapado, asoman tiempos peores. Nada de ello es nuevo. Todos sabemos que éste no es un país sino un club manejado por un puñado de familias y una oligarquía cada vez más rica. Lo peor es que los herederos empiezan a pedir turno.

Estas expresiones indican que las decisiones adoptadas por los dirigentes de Colombia, históricamente consagrados en ese lugar, en la posteridad mantendrán la misma dirección y se- 
rán tomadas por las mismas familias. Se augura entonces con fatalismo y pesimismo el futuro de Colombia sin dejar entrever alternativas posibles, sin hacer mención a los procesos de ejercicio del poder alternativo que se han gestado en las últimas décadas. De manera que la conclusión, "Qué historia la nuestra. Qué futuro nos aguarda", sirve como la consigna en la que se acoge un curso histórico imposible de modificar y en el que se conserva el estado de cosas formulado.

La naturalización en este caso propone al lector la idea de falta de control frente a un estado futuro negativo, al tiempo que representa al ciudadano como pasivo, con baja autoestima y confianza en sí mismo, incapaz de gestar cambios, sometido en el pasado, en el presente y en el futuro a condiciones adversas que lo posicionan en total indefensión. La posibilidad cognitiva que se le deja al lector coincide con el lugar del sujeto cuyas acciones no conducen a la obtención de resultados positivos (en tanto lo compensan o le eliminan las formas de castigo), por lo que éste está abocado a la resignación, aceptación, silencio y apatía. Se formula entonces individuos sometidos a estados de desesperanza aprendida, de acuerdo con los cuales no es posible controlar las contingencias ambientales y, en consecuencia, su comportamiento carece de resultados. Así, frente a la desesperanza sólo es posible un actuar sin pensar y una tendencia a la paralización. La formulación discursiva se estructura para que se reconozca la imposibilidad de acción y, por tanto, se legitime el silencio, en detrimento de la crítica posible.

Esta nota de opinión requiere una observación adicional en relación con su autor, un humorista y escritor con un prontuario extenso en crítica política. Sorprende encontrar en un texto de Daniel Samper Pizano la naturalización de la inequidad y la desigualdad social, máxime cuando se observa que su producción recoge un bagaje de sátiras y críticas frente a las mismas, y sorprende más aún, cuando en el mismo artículo se cuestiona la pervivencia de una oligarquía enajenada de las condiciones sociales. No obstante, mientras elaboraciones conceptuales del tipo "la aplanadora seguirá su marcha. Y como la economía se deteriorará en el 2006 y el TLC espera agazapado, asoman tiempos peores", contribuyen en forma decisiva a la crítica y la ampliación con- ceptual de las políticas de liberación económica y sus efectos desmedidos sobre las condiciones materiales de un grueso número de miembros de la población, la versión fatalista y el mantenimiento de la premisa así ha sido y así seguirá siendo, tal como lo demuestra la historia "Qué historia la nuestra" compromete al texto con la preservación del statu quo.

\section{Vacíos de significación bloqueadores del procesamiento cognitivo}

Una manera de operar de la parálisis cognitiva se explica por la existencia de una gama de supuestos o vacíos de significación, que pueden estimarse como creencias compartidas, conocimiento de sentido común o representaciones que ya están almacenadas en la memoria, que por lo tanto pueden dejarse implícitas. La información que no se hace explícita en muchas ocasiones es compartida y, en consecuencia, la interacción comunicativa goza de fluidez; no obstante en otras se oculta, caso en el cual la interacción comunicativa no favorece la comprensión de los significados discursivos.

\begin{tabular}{|c|}
\hline La naturāeza también se \\
estructura al tratar en el \\
discurso a los conceptos que \\
tienen alto nivel de complejidad \\
y abstracción como si fueran \\
objetos del mundo tangible, así, \\
por ejemplo, las personas bien \\
pueden convertirse en armas o \\
fichas, entre otros, cuando se \\
hace referencia a un conflicto \\
social y político.
\end{tabular}

El ocultamiento hace referencia a la inevitable relación entre conocer y desconocer, lo cual se expresa en el discurso en la puesta en escena comunicativa de conocimientos parciales, errores, relevancia de unos intereses sobre otros, fragmentación, distorsión, espectacularización y dramatización, entre otros recursos. De manera que el discurso público muestra algo distinto de lo que 
debe mostrar, propiciando que ciertos acontecimientos se minimicen, se jerarquicen de manera distinta, e incluso pierdan sentido social. Siguiendo a Bourdieu (1986), el ocultamiento ocurre mediante la selección sistemática de lo sensacional y espectacular, invirtiendo la jerarquía de los acontecimientos, para generar realidades susceptibles de contraste con el mundo.

La siguiente noticia se ocupa de la pobreza y el desplazamiento sin hacer explícitos los responsables de dichos fenómenos y la manera como se ligan con otros fenómenos sociales como el desempleo, el conflicto armado y la distribución de la riqueza.

En Cali hay 400 personas que piden limosna en los semáforos ${ }^{5}$

El drama cotidiano de la capital del Valle es ver en las calles a 500 niños que venden dulces, hacen malabares o se dedican a pedir plata.

Con sus manos extendidas compiten con los vendedores ambulantes en una treintena de cruces de siete de las principales vías de Cali. Hay desde ancianos hasta niños de 3 años.

Son unas 400 personas que acuden a la limosna como subsistencia. No se cuentan los que deambulan por calles del centro o los barrios ni los que venden mercancías o hacen malabares.

Un censo preliminar de la Alcaldía dice que por lo menos 27 'grupos familiares' madrugan a portar carteles que piden limosnas. La mayoría argumenta desplazamiento.

Es el cuadro que está á lá vista en la capital del Valle. La Consejería de Paz de Cali y la Red de Solidaridad hân trabajado en un censo para determinar el número de quienes se instalan al lado de semáforos y aseguran venir de otros lados.

Loss primeros resultados indican que los desplazados se establecen en Cali porque las condiciones de mendicidad tienen algunas ventajas frente a otras ciudades.

A las autoridades les ha llamado la atención en algunos casos hasta la similitud de la letra de los carteles que usan en los semáforos.

\footnotetext{
5 El Tiempo, 30 de ènero de 2006. "En Cali hay 400 personas que pidèn limosna en lòs semáforos". Náción.
}

El secretario de Gobierno, Miguel Yusty, acepta que no es nuevo decir que la mendicidad es un problema y un negocio.

"Lo que ocurre es que en cada época se vuelve a decir que hay una cadena de explotación de adultos y niños. Eso se ha dado en Cali porque no ha existido una política, una actitud, que le diga a los pobladores del Pacífico y del norte del Cauca que no hay condiciones para atender más desplazamiento. Del Eje Cafetero se ha reducido ese movimiento", dijo Yusti.

Cali se alista para la segunda fase del plan maestro de Policía que tendrá como apoyo una plataforma para conocer cuándo llega población nueva y cuánto se quedará. Se medirá realmente cuánta población es posible atender.

'Pobreza en barrios'

Distintos informes indican que Cali es la segunda ciudad colombiana con el mayor número de personas en condición de desplazamiento. El número llegó a estar en 30 familias diarias y serían unas 30.000 personas hace dos años. Se habria reducido, pero no se ha detenido.

$\mathrm{El}$ presidente de la junta comunal del barrio 20 de Julio, Antonio Riascos, dijo que la pobreza no solo viene de afuera, sino que se percibe en los barrios. Considera que no hay políticas nacionales frente al desempleo en una ciudad que atrae a los desplazados.

"Conozco familias que no ven otra salida ante la falta de trabajo y los altos costos de los servicios y la alimentación", señaló Riascos.

En Cali, como en otras capitales, se habla de organizaciones que estarían trayendo adultos y niños desde otros sitios del país e incluso del Ecuador.

El consejero de Paz en Cali, Carlos Rojas, dice que se abrió uná gestión para dialogar con lá Embajada o el Consulado de Ecuador y evaluar el tema.

Este miércoles se abrirá una mesa de trabajo con la Personería, la Defensoría del Pueblo, la Fiscalía y el Das para impulsar en febrero una indagación que precise la existencia de redes organizadas.

"Queremos asumir la tarea con responsabilidad social y proteger la dignidad de quienes hoy, por diferentes razones, están expues- 
tos a riesgos de explotación laboral y sexual", dijo Rojas.

Una de las acciones del sistema institucional será intervenir, en su conjunto y a través de proyectos, a quienes han sido registrados en el censo.

Según la Alcaldía, estas personas pagan entre 6.000 y 10.000 pesos por noche y duermen entre cinco y 10 personas en un cuarto.

La Personería de Cali tiene registrados 492 menores que trabajan en las calles. Sus oficios van desde pedir limosna, vender dulces, actuar de mimos o treparse en columnas humanas a practicar malabares, incluso con fuego. Pero la cifra se queda corta un fin de semana.

Las autoridades les han exigido a los padres de familia que asuman su responsabilidad, pero incluso muchos adultos traen a los niños a los semáforos.

Detrás de los pequeños se habla de personajes que hasta los transportan a sus sitios de trabajo en la vía.

La Autopista tiene mayor romería de quienes piden limosna desde cuando la calle Quinta entró a ser sometida a las obras del MÍO.

Los cruces de las calles 44 y 66 y los de la carrera 70 son los más copados.

Pero en la Quinta el movimiento sí se nota en los cruces de las calles $56,66,80 \mathrm{y}$ 100.

En la avenida Pasoancho la presencia de la mendicidad está centrada en los cruces con la autopista Sur y las calles 44 y 70 . La calle Novena también es agitada. En el norte, en la avenida Tercera, se mueven los cruces con las calles 34,44 y 52 .

Las autoridades conocen algunos casos de personas a las cuales' se les ha ofrecido trabajo, pero se devuelven porque la ganancia puede ir de 5.000 a 40.000 pesos.

Vendedores ambulantes como Julio Rojas, con una caja de dulces, se quejan de que ganan más dinero quienes piden limosna.

En esta noticia se referencian diferentes situaciones sociales: pobreza, desplazamiento, desempleo, mendicidad, explotación laboral y sexual, trabajo infantil, política pública en mate- ria social, informalidad y pobreza, por mencionar los temas principales. Esta mezcla de situaciones no permite diferenciar las 400 personas que subsisten con la limosna, pues se habla de 500 niños, de 27 familias e invitan a considerar que "No se cuentan los que deambulan por calles del centro o los barrios ni los que venden mercancías o hacen malabares", con lo cual se excluye a un sector de la indigencia. Además, se intenta proponer un mapa de la ciudad en términos de la situación de 'perdir limosna' dejando de lado la ubicación exacta: "en una treintena de cruces de siete de las principales vías de Cali, Los cruces de las calles 44 y 66 y los de la carrera 70 son los más copado". Se menciona unas características de facilidad para la mendicidad en Cali sin especificarlas: "Los primeros resultados indican que los desplazados se establecen en Cali porque las condiciones de mendicidad tienen algunas ventajas frente a otras ciudades". Se intenta proponer una evidencia comparativa resultado de trabajos investigativos sin indicar las otras ciudades con las que es contrastada Cali, ni la cantidad de informes, ni las instituciones que los elaboraron: "Distintos informes indican que Cali es la segunda ciudad colombiana con el mayor número de personas en condición de desplazamiento".

Llama la atención la manera como se intentan asociar las distintas situaciones sociales tratadas en la noticia: "A las autoridades les ha llamado la atención en algunos casos hasta la similitud de la letra de los carteles que usan en los semáforos, y Según la Alcaldía, estas personas pagan entre 6.000 y 10.000 pesos por noche y duermen entre cinco y 10 personas en un cuarto". Nótese cómo en este caso los acontecimientos indicados conforman una gama de retazos aislados, cuyas conexiones se amparan en supuestos implícitos y explícitos del tipo: quienes piden limosna son los desplazados o provienen de redes de explotación o lo hacen porque les trae beneficios con pocos esfuerzos, entre otros. La fragmentación de los acontecimientos, así como el uso sin reparo de una amplia gama de términos que refieren a fenómenos sociales distintos, junto con la ausencia información específica espacial, de causas de la mendicidad, de límites entre una situación social y otra, de concreción y especificidad de las citaciones a las que 
se hace referencia, terminan por establecer un vacío en la significación.

En este sentido, cuando se lee un artículo como el anterior no es posible inferir el concepto de persona que pide limosna, ni determinar quiénes son los responsables de que un estado de cosas como éste se genere y siga su curso. Sumado a lo anterior, se niega el acceso al conjunto de relaciones que se sugieren entre indiǵencia, mendicidad, desplazamiento y explotación. Todo esto configura desde la fragmentación y la falta de significados lo que se denomina ocultamiento. El nexo que se establece entre el ocultamiento y la parálisis cognitiva implica entonces la idea de que el procesamiento requiere un conjunto de conceptos y relaciones entre éstos, que permitan la representación de las realidades que se proponen.

\section{Abriendo el debate}

La parálisis cognitiva es tan sólo la metáfora a través de la cual se sintetiza el efecto de expresiones emotivas, el uso de lo natural para reducir la complejidad de lo social y la función de la información completa en el momento de estructurar los discursos. En estos casos, el miedo, la ira, la rutina, la cotidianidad, lo natural y el desconocer se convierten en los principales efectos de construcción discursiva a estudiar, de cara a las múltiples implicaciones que tienen en la comprensión y producción de significados. Tal como se indicó, la parálisis funciona a través de tres procesos

El ocultamiento hace referencia
a la inevitable relación entre
conocer y desconocer, lo cual
se expresa en el discurso
en la puesta en escena
comunicativa de conocimientos
parciales, errores, relevancia
de unos intereses sobre otros,
fragmentación, distorsión,
espectacularización y
dramatización, entre otros
recursos.

discursivos fundamentales: espectacularización, ocultamiento y naturalización. Con respecto a este último, es crucial hacer una distinción entre la naturalización entendida como la tendencia a proponer representaciones de las situaciones con sus actores y acciones construidas como referentes normativos; habituales, legítimos o deseables, en los que priman rasgos esenciales, que recogen estigmas e invisibilizan la alteridad, y aquella consideración de la lingüística cognitiva en la que con base en la experiencia vital elaborada desde la corporalidad se soporta todo el esquema conceptual de la especie y, en consecuencia, todo concepto constituye una analogía de la orientación espacio-temporal y la caracterización ontológica (objeto, sustancia y recipiente), en primera instancia, y del conjunto de metáforas culturales dominantes, en segunda instancia.

En este sentido, la teoría del realismo experiencial, más que una naturalización de los acontecimientos, es una explicación evolutiva de la forma como se estructuran los conceptos. Esto se distancia del hecho de que el funcionamiento de lo social se conceptualice en los mismos términos del funcionamiento de lo natural. Así, la conceptualización con base en el razonamiento analógico no implica necesariamente una formulación esencialista, habitual, normal y perdurable de las situaciones, como ocurre cuando la conceptualización se ha naturalizado.

De manera que cuando se considera a la parálisis cognitiva como el resultado de procesos de espectacularización, naturalización y ocultamiento, se hace hincapié en la vigencia de consensos sociales propios de modelos culturales. Esto indica que la elaboración discursiva que funciona como génesis de la parálisis cognitiva encuentra un conjunto de determinantes culturales, es decir, de modelos de interacción y comprensión, en virtud de los cuales es posible obtener efectos emotivos, vacíos de significación y formas estándar de comprensión de la realidad. De acuerdo con lo señalado, los determinantes culturales guardan relación con el reconocimiento del papel del tabú sobre las reacciones emotivas, como cuando se narra la muerte; con la superioridad del complejo mundo natural frente a las acciones individuales de 
la especie humana (los instintos, los fenómenos climáticos y geológicos, el curso del tiempo, entre otros, son incontrolables) y con el bagaje de significados necesarios para la comprensión ( $p$. ej. ingreso se comprende si se tiene conceptos como empleo, ganancia, trabajo, entrada). Ó

\section{Bibliografía}

ANTA FÉLEZ, J. L. (1999). Desesperación y búsquedas. La antropología social y el (des) encuentro con la ciencia. En: Gazeta de Antropología, No 15. Universidad de Jaén. Ubicación virtual: http://www.ugr.es/ pwlac/ G15_10JoseLuis_Anta_Felez.html

AUGOUSTINOS, M. y WALKER, I. (1995). Social Cognition, An integrated Introduction. London: Sage Publications.

BOURDIEU, P. (1986). Distinction: A social critique of the judgment of taste. Cambridge: Cambridge University Press.

BOURDIEU, P. (1997). Sobre la televisión. Barcelona: Anagrama.

Consejo transitorio de administración regionalpiura, Cooperación alemana al desarrollo, Instituto interamericano de cooperación para la agricultura y Centro de investigación y promoción del campesinado (2000). Planeamiento estratégico regional Proyecto Piura 2010. Plataforma de concertación regional. Ubicación virtual: http://www. cipca.org.pe/cipca/webir/regpiura/proyecto1.htm

CHAFE, W. (1990). "Some things that narratives tell us about the mind". En: Bruce, Britton y Pellegrini (eds) Narrative thought and Narrative Language. Hillsdale, N.J: Lawrence Erlbaum.

DRETSKE, F. (1986). "Misrepresentation". En: Mind and Cognition, a reader, 1990. Oxford: Oxford University Press.

FEUERSTEIN, R. (1991). Cultural difference and cultural deprivation. Differential patterns of adaptability. En: N. Bleichrodt y P. Drenth (Eds.), Contemporary issues in cross-cultural psychology. Amsterdam: Swets \& Zeitlinger.

GAETA, R. (2004). Realismo, Bootstrapping y conocimiento. En: Martins, R. A.; Martins,
L. A. C.; Silva, C.C. y Ferreira, J. M. H. (eds) Filosofía e história da ciencia no Cone Sul: $3^{\circ}$ Encontro. Campinas: AFHIC. Pp 421-428. Ubicación virtual: http://ghtc.ifi. unicamp.br/afhic3/Trabalhos/57-RodolfoGaeta.pdf

GARDNER, H. (1985). La nueva ciencia de la mente: Historia de la revolución cognitiva. Barcelona: Paidós.

GUEBEL, D. (1998). Verdurita y revolución. En: Clarín.com, Revista N. Ubicación Virtual http://www.clarin.com/suplementos/ cultura/1998/11/08/e-01401d.htm

LANGACKER, R. (1987). Foundations of Cognitive Grammar. Vol 1. Stanford: Stanford University Press.

LAKOFF, G. (1987). Women, fire and dangerous things: What categories reveal about the mind. Chicago: University of Chicago Press.

LAKOFF, G. y JOHNSON, M. (1980). Metáforas de la vida cotidiana. Madrid: Cátedra (1986).

LAKOFF, G. y JOHNSON, M. (1999). Philosophy in the flesh. New York: Basic Books.

LICHTENBERG, J. D. (2004). Sistemas motivacionales y escenas modelos con especial referencia a la experiencia corporal. En: Revista de Psicoanálisis Aperturas Psicoanalíticas. No. 17 Ubicación virtual: http://www.aperturas.org/17lichtenberg. html\#notasterisco

MACLEOD, C. y MATHEWS, A. (1988). Anxiety and the allocation of attention to threat. En: Quarterly Journal of Experimental Psychology, 40A, 653-670.

MILLIKAN, R. (1992). The white queen psychology and other essays for Alice. Cambridge: MIT Press.

SPERBER, D. y WILSON, D. (1986/1994). La relevancia. Madrid: Visor.

VON ECKARDT: (1999). "Mental Representation". En: The MIT Encyclopedia of the Cognitive Sciences. Cambridge: MIT Press.

WILLIAMS, J. M. G., MATHEWS, A. y MACLEOD, C. (1996). The emotional stroop task and psychopathology. En: Psychological Bulletin, 120, 3-24. 